J. Geom. 98 (2010), 21

(C) 2010 Springer Basel AG

0047-2468/10/010021-1

published online October 26, 2010

DOI 10.1007/s00022-010-0050-2

Journal of Geometry

Erratum

\title{
Erratum to: Monotone and Čebyšev arcs in hyperspaces
}

Robert J. MacG. Dawson

\section{Erratum to: J. Geom.}

\section{DOI 10.1007/s00022-010-0044-0}

In this article, the following changes should be made.

1. Proposition 5.4 (ii) should read:

A monotone arc indexed by $(0,1]$ in $\mathcal{K}_{0}^{n}$ or $\mathcal{O}_{0}^{n}$ attains its infimum distance from every element of the hyperspace if and only if it is unbounded or is nested and collapses at 0 .

2. Theorem 5.6 should read:

A monotone arc in $\mathcal{K}_{0}^{n}$ is Čebyšev if and only if it is nested and at either end it is closed, is unbounded, or collapses.

3. Theorem 5.8 should read:

A monotone arc in $\mathcal{O}_{0}^{n}$ is Čebyšev if and only if at either end, it is closed, is unbounded, or is nested and collapses.

Robert J. MacG. Dawson

Department of Mathematics and Computing Science

Saint Mary's University

Halifax, NS B3L 3C3, Canada

e-mail: rdawson@cs.stmarys.ca

The online version of the original article can be found under doi:10.1007/s00022-010-0044-0. 